\title{
Norteamentos da política de formação dos professores da educação básica no Brasil (2007-2014)
}

Melânia Mendonça Rodrigues

Universidade Federal de Campina Grande

\section{Resumo}

artigo objetiva explicitar, criticamente, norteamentos da política de formação dos professores para a educação básica brasileira, no período 2007-20 14, apontando aproximações das indicações de organismos multilaterais e do governo federal brasileiro. Nessa direção, toma, como fonte e objeto de análise, documentos da Organização para a Cooperação e Desenvolvimento Econômico (OCDE), do Banco Mundial (BM) e do Instituto de Pesquisa Econômica Aplicada (IPEA), respectivamente. Articulada à literatura referente à política de formação de professores da educação básica na primeira década do século XXI, a análise das referidas orientações constata convergências das formulações do IPEA às da OCDE e BM, no que concerne à fragilização da formação inicial do docente, bem como aponta para o risco de a formação universitária ser substituída por certificações alternativas, ou por provas nacionais de ingresso no magistério, permitindo atrair profissionais de outras áreas para o exercício profissional como professores.

Palavras-chave: Política educacional. Formação de professores. Certificação de professores. Educação Básica.

\section{Guidelines for training teachers policy for elementary education in Brazil (2007-2014)}

\section{Abstract}

This article aims to explain, critically, guidelines of the teacher training policy for Brazilian elementary education, in the period 2007-2014, indicating its approximations from the guidelines presented by multilateral organizations and the Brazilian federal government. In this direction, it takes, as source and subject of analysis, documents of the Organization for Economic Cooperation and Development (OECD), the World Bank and the Brazilian Institute of Applied Economics Research (originally IPEA), respectively. Linked to the literature on the policy of teacher education in elementary education in the first decade of the 21 st century, the analysis of these guidelines confirms the convergence of the IPEA formulations and those by the OECD and World Bank, regarding the weakening of initial teacher education, as well as points to the risk that the university education will be replaced by alternative certificates or national exams to join the magisterium, allowing to attract professionals from other areas to practice as teachers.

Keywords: Educational policy. Teacher training. Teachers certification. Elementary education. 


\section{Direccionamientos de la política de formación de los profesores de la educación básica en Brasil (2007-2014)}

\section{Resumen}

El artículo objetiva explicitar, críticamente, direccionamientos de la política de la formación de profesores para la educación básica brasileña, en el período 2007-20 14 , apuntando aproximaciones de las indicaciones de organismos multilaterales al gobierno federal brasileño. En esa dirección, toma como fuente e objeto de análisis documentos de la Organización para la Cooperación y el Desarrollo Económico (OCDE), del Banco Mundial (BM) y del Instituto de Pesquisa Económica Aplicada (IPEA), respectivamente. Articulada a la literatura sobre la política de formación de profesores de la educación básica en la primera década del siglo XXI, el análisis de las referidas orientaciones constata convergencias de las formulaciones del IPEA con la OCDE y BM, en lo que concierne a la fragilización de la formación inicial del profesor, así como apunta para el riesgo de que la formación universitaria sea sustituida por certificaciones alternativas, o por exámenes nacionales de ingreso en el magisterio, permitiendo atraer profesionales de otras áreas para o ejercicio profesional como profesores.

Palabras clave: Política educacional. Formación de profesores. Certificación de profesores. Educación Básica.

\section{Introdução}

artigo busca explicitar, criticamente, norteamentos da política de formação dos professores para a educação básica brasileira, no período 2007-2014, apontando aproximações das indicações de organismos multilaterais e do governo federal brasileiro. Decorre de um estudo motivado pela constatação de que, no período considerado, mesclaram-se, de modo aparentemente paradoxal, um aumento da certificação no nível superior e um amesquinhamento dessa formação (RODRIGUES, 2015), tanto na dimensão técnico-científica quanto na ético-política, concernentes, entre outros aspectos, à diversificação institucional, ao predomínio da iniciativa privada na formação docente e à formação continuada na modalidade EaD.

Ultrapassada a aparência, tal impressão de paradoxo cede lugar à constatação de uma política coerente e fortemente articulada, compreendendo ambas as referidas dimensões da formação, assentada em uma concepção de professor e em uma intencionalidade acerca do seu papel social, consentâneas com os imperativos do "contexto do capitalismo tardio" (FRIGOTTO, 2011 ) cuja formulação, em grande medida, origina-se em organismos internacionais como o Banco Mundial (BM) e a Organização para a Cooperação e 
Desenvolvimento Econômico (OCDE) conforme buscamos explicitar na sequência do presente texto.

\section{A indução dos organismos internacionais nas políticas de formação de professores para a educação básica}

Fenômeno já fartamente estudado na literatura acadêmica, a crise de endividamento dos países do Terceiro Mundo, na década de 1980, propicia um contexto político favorável para que organismos internacionais de financiamento, como o BM (Banco Mundial) e o FMI (Fundo Monetário Internacional), assumam um papel central na orientação e monitoramento das denominadas políticas de ajuste estrutural.

Além dessas políticas, o Banco Mundial, compreendendo a importância estratégica da educação na consolidação da racionalidade do neoliberalismo de mercado, procede à definição de diretrizes para área e, mais especificamente, para a formação de intelectuais para o exercício da docência na educação básica, visando ao controle da mente "[...] do pequeno núcleo de intelectuais, dos educados e dos semieducados" (LEHER, 1999, p. 20).

Dessa forma, as propostas do Banco Mundial tencionam que os docentes ensinem e que os discentes adquiram competências, bem como desenvolvam aptidões, valores e atitudes, de acordo com as novas demandas de reprodução técnico-científica e ético-política do capital.

Mantendo-se o BM como organismo de relevante ingerência nas políticas educacionais brasileiras, os anos 2000 marcam uma "vinculação mais umbilical" (MELO; SOUZA; MELO, 2015, p. 48) do país à OCDE, consubstanciada, entre outras, na participação - como membro associado, participante ou convidado - em 36 instâncias da Organização, entre os quais, o Conselho Diretor do Programa Internacional de Avaliação de Estudantes (PISA), do qual é vice-presidente desde 2013 (BRASIL, 2015)

Analisando essa aproximação de uma perspectiva crítica, Maués (2011) chama a atenção para a relevância do papel que a OCDE vem assumindo no tocante às políticas educacionais, pela realização e divulgação de pesquisas, pela publicação de documentos ou "[...] pelo 'aconselhamento' oferecido tanto aos países membros como aos outros" (p. 76). Em se tratando, 
mais especificamente, das políticas de formação docente, a autora destaca, como características principais, a valorização instrumental, a ênfase na eficácia e na performance, bem como a "[...] adoção de formas de controle que incidem sobre os resultados, com um discurso de autonomia sobre o processo" (MAUÉS, 2011 , p. 83).

Considerando, pois, a OCDE e o Banco Mundial como os organismos multilaterais mais influentes nas políticas educacionais brasileiras no período aqui estudado, passamos a apresentar suas orientações para a formação dos professores, expressas, respectivamente, nos documentos "Professores são importantes: atraindo, desenvolvendo e retendo professores eficazes" (OCDE, 2006) e "Profesores excelentes: como mejorar el aprendizaje en América Latina y el Caribe" (BRUNS; LUQUE, 2014). Entendemos que este último documento pode ser considerado como expressão das concepções do Banco por haver sido construído e publicado sob seus auspícios, tendo por autores intelectuais orgânicos desse organismo multilateral.

Importa esclarecer que, ao falarmos da influência dos organismos multilaterais na educação brasileira, compreendemos tratar-se de uma híbrida relação de "intervenção e consentimento" (SILVA, 2002), na qual, de um lado,

114 tais organismos, "[...] articulados aos interesses dos países capitalistas hegemônicos" [...] estabelecem diretrizes, buscando "[...] produzir, nas diferentes regiões do mundo, um professor com inúmeros elementos em comum, instrumentalizado com objetivos assemelhados" (EVANGELISTA; SHIROMA, 2007, p. 533). De outro lado, a implementação de tais diretrizes não se faz sem "[...] a participação efetiva do Estado e [...] a aquiescência dos diferentes níveis de ação, seja o Ministério da Educação ou Secretarias, direção de estabelecimentos e os próprios professores" (MAUÉS, 2011 , p. 83).

\section{Professores eficazes?}

Resultante de estudo sobre políticas para professores, realizado, pela OCDE, no período 2002-2004, a publicação Professores são importantes: atraindo, desenvolvendo e retendo professores eficazes apresenta as sínteses construídas com base nos Relatórios de Background (26 relatórios, de 25 países) e nos relatórios de visitas de acompanhamento (dez relatórios, de nove países). 
Além dos elementos introdutórios - prólogo, resumo executivo e introdução (Capítulo 1) 1 -, estrutura-se em seis capítulos (Capítulos 2 a 7) $)^{2}$, nos quais se distribuem os três eixos norteadores do estudo. Complementarmente, inclui dois apêndices, que, respectivamente, discriminam aspectos metodológicos e "[...] fornece[m] uma estrutura de indicadores para instruir políticas para professores, e avalia a disponibilidade [...] de dados nos níveis nacional e internacional" (OCDE, 2006, p. 21). À exceção dos capítulos dois e sete, todos os demais apresentam idêntica organização: itens que descrevem e analisam as políticas desenvolvidas nos países estudados, com destaque às experiências de sucesso, arrematados com um último, definindo prioridades para o futuro desenvolvimento de políticas.

Justificando, logo no Prólogo, a realização do estudo e, simultaneamente, o título adotado para sua publicação, o Diretor para a Educação da OCDE expressa as "sérias dificuldades" enfrentadas, pelos ministros de Educação dos países-membros, em "recrutar professores qualificados" (OCDE, 2006 , p. 3) para suprir a escassez decorrente da aposentadoria de grande contingente de docentes, antes do final da segunda década dos anos 2000.

Tal preocupação, como ficará patente ao longo do documento, decorre do reconhecimento da "alta prioridade" das políticas para professores nas agendas nacionais, respaldada na compreensão de que esses profissionais, constituindo o "[...] recurso mais significativo das escolas, são fundamentais para os esforços de aprimoramento dessas instituições", cuja "alta qualidade" assume [...] uma importância nunca antes vista" [...] ante as mudanças econômicas e sociais de grande alcance em andamento" (OCDE, 2006, p. 7).

Abordando, de modo abrangente, formação e profissão docente, e guardando plena coerência interna, o referido documento é articulado com base nas concepções neotecnicistas e neoprodutivistas (SAVIANI, 2007), de modo que a pedagogia das competências constitui o fundamento teórico da formação, a racionalidade econômica determina a organização dos cursos, e os requisitos da polivalência e da performatividade (foco no desempenho e nos resultados) - com os seus correlatos de intensificação do trabalho e de responsabilização dos docentes - pautam o trabalho do professor.

No presente artigo, focalizaremos apenas o capítulo relativo à formação docente (Capítulo 4), Desenvolvendo conhecimentos e habilidades de 
professores, composto pelos seguintes itens: Os papéis dos professores estão mudando; Implicações de pesquisas sobre professores eficazes; Educação inicial de professores; Certificação de novos professores; Programas de iniciação para novos professores; Desenvolvimento profissional, e Prioridades para o desenvolvimento de políticas futuras. Desses itens, não abordaremos os referentes aos programas de iniciação para novos professores - de cunho mais descritivo, ratificando formulações já contidas em itens anteriores do documento - e ao desenvolvimento profissional, por se voltar à formação continuada, da qual não tratamos neste momento.

\section{Professor (multi)tarefeiro}

Sob o título "Os papéis dos professores estão mudando", e com base no pressuposto de que "mudanças sociais" aumentam e tornam mais complexas as exigências postas às escolas e aos professores, o documento preconiza que "[...] professores devem ser capazes de preparar estudantes para uma sociedade e uma economia em que se espera sejam aprendizes autodirigidos, $116 \quad$ 2006, p.1011.

Assim, "[...] a maioria dos Relatórios Nacionais de Background" apresenta a expectativa de que os professores "desempenhem papéis muito mais amplos" (OCDE, 2006, p. 101), configurando as denominadas "áreas de responsabilidade ampliada dos professores", quais sejam:

- no nível de cada estudante - lançamento e gerenciamento de processos de aprendizagem; resposta eficaz às necessidades de aprendizagem de cada aprendiz; integração de atividades formativas e cumulativas;

- no nível da sala de aula - ensino em salas de aula multiculturais; nova ênfase transcurricular; integração de estudantes com necessidades especiais;

- no nível da escola - trabalho e planejamento em equipe; avaliação e planejamento sistemático de aprimoramento; utilização das Tecnologias da Informação e Comunicação (TIC) em ensino e administração; projetos entre escolas e cooperação internacional; gerenciamento e liderança compartilhada;

- no nível dos pais e da comunidade ampla - oferta e aconselhamento profissional para os pais; estabelecimento de parcerias comunitárias para a aprendizagem (OCDE, 2006). 
Ademais, os Relatórios ainda apontam, segundo o documento referenciado, a expectativa de que "[...] os professores atuem como pesquisadores e solucionadores de problemas, refletindo sobre sua própria prática e assumindo maior responsabilidade por seu próprio desenvolvimento profissional" (OCDE, 2006, p. 1031.

Em nossa compreensão, temos, aqui, uma dupla desfiguração da peculiaridade da docência: a primeira, uma agudização e alargamento do perfil de professor tarefeiro (KUENZER, 1999), ampliando o espectro de responsabilização funcional do docente com tarefas de caráter nitidamente gerencial e operacional. Sequer "no nível de cada estudante", é apontado o papel do professor como mediador da apropriação, pelo aluno, do conhecimento social e historicamente construído pela humanidade.

A segunda desfiguração, além do explícito primado do "professor reflexivo", aproxima as proposições da OCDE à vertente administrativa da Teoria do Capital Humano (TCH), mediante a proposta dessa Organização de que os professores devem assumir "[...] maior responsabilidade por seu próprio desenvolvimento profissional" (OCDE, 2006, p. 103) torna o trabalhador "uma espécie de empreendedor" a quem cabe investir, pessoalmente, em sua qualificação (DAVENPORT, 1999 apud PIRES, 2005, p. 77).

\section{Formação rarefeita}

Os três itens seguintes - Implicações de pesquisas sobre professores eficazes, Educação inicial de professores e Certificação de novos professores - do ora considerado Capítulo 4, ao mesmo tempo que constituem objetivações das concepções neotecnicistas e neoprodutivistas, como indicamos na introdução da seção "Professores eficazes", convergem para restringir a dimensão teórica e minimizar a relevância da formação inicial dos professores da educação básica.

Com efeito, iniciando com uma genérica definição de professores eficazes - "[...] pessoas intelectualmente capazes, articuladas e versadas, que conseguem raciocinar, comunicar-se e planejar de maneira sistemática" ou "professores competentes em diversas áreas" (OCDE, 2006, p. 104) -, o tópico Implicações de pesquisas sobre professores eficazes reúne uma série de avaliações que, a nosso ver, cumprem duas finalidades principais, a primeira 
das quais, secundarizar a importância de uma sólida formação acadêmica, por meio de afirmações como: "[...] há um patamar de conhecimento relacionado a disciplinas específicas necessário para professores eficazes"; "[...] altos níveis de conhecimento relacionado a disciplinas específicas - ao menos em termos de qualificações acadêmicas - não estão necessariamente relacionados a ganhos para os estudantes [...], as pesquisas defendem apenas moderadamente a importância de conhecimentos sólidos em disciplinas específicas"; "[...] as evidências são menos claras com relação aos benefícios de qualificações avançadas em educação" (OCDE, 2006, p. 104-105).

A segunda finalidade consiste em reforçar a performatividade e a lógica do controle pela avaliação, mediante, respectivamente, a identificação de competências e habilidades pessoais "[...] que fazem a diferença na qualidade e na eficácia do ensino" e o reconhecimento da necessidade do estabelecimento de "padrões de eficácia de professores". Segundo o documento, "[...] um número crescente de países vem desenvolvendo perfis e padrões docentes comuns, de acordo com os quais a educação e o desenvolvimento de professores e as condições nas escolas podem ser avaliados" (OCDE, 2006, p. 106).

118 No terceiro item do Capítulo 4, Educação inicial de professores, tornam-se recorrentes, como balizamentos para as análises referentes aos cursos de formação inicial, os argumentos respaldados na lógica economicista e a ênfase à atração, para a docência, de pessoas com formação em outras áreas.

Inicialmente, são apresentados, com breves apreciações, os dois modelos de formação de professores vigentes nos países pesquisados - modelos simultâneos e modelos consecutivos ${ }^{3}$. Em nossa interpretação, o documento inclina-se para o segundo modelo, uma vez que são pródigas as críticas ao primeiro: são pouco flexíveis; exigem opção precoce, por parte dos alunos; podem dificultar e encarecer o ingresso de graduados em alguma disciplina; podem ser menos atraentes onde as perspectivas de trabalho de professores são incertas; podem ser menos atraentes para outros empregadores potenciais (OCDE, 2006).

Quanto ao modelo consecutivo, apenas uma crítica é apresentada, concernente ao risco de "[...] desenvolvimento de uma experiência de aprendizagem menos integrada para futuros professores [... $]^{\prime \prime}$, enquanto são apontados 
diversos argumentos favoráveis: ingresso flexível; momento de decisão mais tardio; acomodação mais rápida a mudanças nos interesses dos estudantes e nas condições do mercado de trabalho; " [...] educação potencialmente mais intensa no caso de áreas específicas, uma vez que disciplinas como matemática, história e outras têm maior probabilidade de serem lecionadas por especialistas" (OCDE, 2006, p. 110 , grifo meu).

Trilhando, ainda, a mesma direção analítica, o documento discute a duração dos "programas de educação de professores", contrapondo programas curtos a longos. Novamente, embora sejam apontadas indicações acadêmico-profissionais - responsabilidades mais abrangentes dos professores, status similar das qualificações docentes ao de outras profissões - favoráveis a uma formação inicial mais longa, prevalecem as ponderações de que "[...] cursos mais longos levam a custos mais altos [...]", enquanto cursos de duração relativamente curta [...] facilitam o ingresso na docência de pessoas vindas de outras carreiras, visto que envolvem custos mais baixos, especialmente em termos de custos de oportunidade" JOCDE, 2006, p. 111 112 ). Consequentemente, o documento indica que "[...] pode ser mais válido fornecer mais recursos para aprimorar o desenvolvimento de professores ao longo de suas carreiras do que aumentar a duração da educação pré-serviço" (OCDE, 2006, p. $112-113$ ).

De questionada, nos fragmentos que vimos de transcrever, sob o prisma financeiro, a formação inicial de professores é alvo, no item Certificação de novos professores, de um crescente progresso de desqualificação. De início, a formação inicial e as instituições que a promovem são colocadas em posição subalterna à certificação, por afirmações como "[...] a certificação de professores permite o estabelecimento de padrões profissionais, que são independentes de instituições de capacitação de professores [...]" ou [...] esta [a certificação] é uma forma de influenciar programas de educação de professores e de alinhá-los com maior precisão às necessidades das escolas" (OCDE, 2006, p. 122).

Na sequência, a formação inicial torna-se dispensável, dado que "[...] formas alternativas de certificação vêm sendo utilizadas em alguns países para permitir que ingressem na docência indivíduos que, embora qualificados, não concluíram um programa de educação de professores" (OCDE, 2006, p. 122, grifo meu). 
Segundo o documento, cerca de "[...] dois terços dos países participantes oferecem programas alternativos de educação de professores para 'ingressantes por caminhos alternativos [...]'" (OCDE, 2006, p. 1 15). O documento ressalta, ainda, que, nos Estados Unidos,

Esses programas oferecem grande flexibilidade, atraindo novos tipos de candidatos à docência - inclusive pessoas potencialmente muito capazes, que de outra forma não ingressariam na docência -, além de geralmente implicarem baixos custos (OCDE, 2006, p. 117, grifo meu).

E, culminando sua desqualificação, a formação inicial resulta irrelevante, visto que subsumida à lógica do desempenho imanente à certificação, conforme aponta o documento da OCDE, como "a tendência geral":

[...] mudanças nos requisitos exigidos para certificação de professores, que deixam de ser medidas de formação (como um número de cursos frequentados ou de créditos), passando a ser critérios de resultados - mais especificamente conhecimentos, habilidades e competências medidas de maneiras variadas (OCDE, 2006, p. 123, grifo meu).

\section{Das constatações às proposições}

Com respaldo nos dados coletados, a OCDE traça Prioridades para o desenvolvimento de políticas futuras, ponderando que tais prioridades não se aplicam, da mesma forma, a todos os países. Ademais, alerta que, "[...] em alguns casos, não há base de pesquisa suficiente que tenha sido realizada por um número suficiente de países para gerar confiança no sucesso de sua implementação" (OCDE, 2006, p. 139, grifo meu).

Feitas essas ressalvas, o documento traz uma dezena de proposições, das quais recolhemos aquelas que julgamos mais expressivas.

- Desenvolvimento de perfis de professores para alinhar desenvolvimento de professores, padrões de desempenho e necessidades das escolas - "prioridade mais difundida", a definição do perfil claro e conciso de competências do professor pressupõe o estabelecimento de objetivos claros para a aprendizagem de estudantes. Ou seja, "[...] o perfil dos professores deve refletir a 
ampla variedade de competências que devem ter para que atuem de maneira eficaz em escolas modernas" (OCDE, 2006, p. 139).

- Considerando o desenvolvimento docente como um continuum - ratificando que a educação inicial é insuficiente para atender às necessidades de professores e escolas, o documento frisa que "[...] a educação de professores pré-serviço continuará a ser importante, mas passará a ser vista como um meio de fornecer as bases para o desenvolvimento dos professores" (OCDE, 2006, p. 140).

- Tornando a educação inicial de professores mais flexível e reativa-são apresentadas "características de um sistema educacional flexível e reativo", cuja clareza exige sua completa transcrição:

- oportunidade para adquirir capacitação como professor após ter concluído estudos em outra área (programas consecutivos, pós-graduação, programas simultâneos);

- estruturas curriculares modulares, que permitam que as pessoas se matriculem em educação em período parcial ou a distância e que combinem a educação de professores com responsabilidades de trabalho ou familiares;

- aumento nos componentes comuns da formação de professores para diferentes tipos de escolas e de níveis educacionais, visando ampliar as oportunidades de trabalho em escolas diferentes à medida que mudam a demanda e os interesses de carreira dos professores;

- caminhos alternativos para a docência para indivíduos em meio de carreira que desejam mudar de rumo, combinando estudo formal e apoio em serviço com redução na carga horária de ensino;

- créditos para qualificações e experiência adquiridas fora da educação, de modo a reduzir a duração e os custos de cursos;

- programas de recapacitação e aprimoramento, que permitam que os professores adquiram novas qualificações para lecionar em outros tipos de escolas ou para assumir áreas de estudo de alta demanda;

- estabelecimento de relações estreitas com escolas, empregadores de professores e com a profissão docente;

- pesquisas e desenvolvimento de atividades focadas em questões relacionadas a escolas e professores;

- desenvolvimento de mecanismos de feedback e de avaliação que possibilitem o monitoramento e o aumento da qualidade 
dos resultados da educação de professores (OCDE, 2006, p. 140-1411.

- Aprimoramento da seleção para educação de professores - os países deverão implantar políticas que aumentem a "[...] atratividade da docência como opção de carreira para pessoas competentes e motivadas [...]", bem como, "[...] utilizar critérios de seleção que garantam que os melhores candidatos possíveis ingressem em programas de educação de professores" IOCDE, 2006, p. 141).

- Mudanças na ênfase na educação inicial de professores - coerentemente com a primeira indicação, aqui é proposto que os cursos de formação inicial "[desenvolvam] as habilidades para a prática reflexiva e a pesquisa sobre o trabalho" (OCDE, 2006, p. 142).

- Credenciamento de programas de educação de professores - segundo o documento, o credenciamento, "[...] por parte de uma agência independente e confiável, é um meio de assegurar qualidade na educação de professores e de ajudar a garantir que os recursos sejam bem utilizados e que os professores recebam boa formação". A OCDE recomenda que "[...] critérios de creden-

122 ciamento devem dar maior atenção aos resultados de programas e não a seu conteúdo, seus currículos e seus processos" (OCDE, 2006, p. 143).

- Certificação de novos professores - a certificação é recomendada como um mecanismo de definição de padrões profissionais aplicáveis aos futuros professores, qualquer que seja sua formação. Pode, ainda, "fornecer meios para que indivíduos de diferentes backgrounds tornem-se professores" (OCDE, 2006, p. 1431.

A apresentação, por nós procedida, do documento Professores são importantes: atraindo, desenvolvendo e retendo professores eficazes ratifica nosso entendimento de que as propostas da OCDE visam ao barateamento dos custos, ao aligeiramento e à desqualificação da formação inicial do professor, como também, à subordinação do seu trabalho aos requisitos da performatividade. Permite-nos, ainda, concordar com Souza (2009, p. 151), para quem, "[...] a mão de obra docente, na proposta da OCDE, pode ter formação inicial em qualquer área, para facilitar a mobilidade entre empregos e trabalhos temporários". 
Mas, em nosso entendimento, ao longo de todo o texto produzido pela $O C D E$, sobressai-se um elemento ainda mais grave: o escárnio com que são tratados os professores licenciados. A ênfase em rotas alternativas e certificação de graduados em outras áreas "que, de outra forma, não ingressariam na docência", sempre acompanhadas da justificativa de serem mecanismos para atrair pessoas competentes, "os melhores candidatos", vai afirmando, insidiosamente, o julgamento de que, à licenciatura, destinam-se os incompetentes, os piores candidatos.

\section{Professores excelentes?}

Escolhemos focalizar o documento Profesores excelentes: cómo mejorar el aprendizaje en América Latina y el Caribe, embora sua publicação tenha ocorrido no último ano abrangido por nosso estudo (2014), seja porque baseia suas formulações em pesquisas realizadas ainda na primeira década dos anos 2000, seja pela consonância das suas orientações com as formulações da OCDE e, principalmente, por percebermos objetivações de propostas nele contidas na política de formação de professores implementada no Brasil, no período 2007-2014. Ademais, a consonância dos dois documentos, elaborados nos anos-limite desse período, indica, em nosso entendimento, a consistência e a conservação dessas orientações, para os organismos multilaterais considerados.

Publicado pelo Grupo Banco Mundial, integrando a Serie del Foro sobre Desarrollo de América Latina, o documento Profesores excelentes: cómo mejorar el aprendizaje en América Latina y el Caribe, conforme esclarecem seus autores e coordenadores da pesquisa, Barbara Bruns e Javier Luque, resulta de um trabalho realizado por uma equipe no âmbito do programa de Estudos Regionais sobre América Latina e Caribe, do Banco Mundial.

Segundo os autores, esse estudo assume relevância pelo fato de os professores desempenharem o papel de "[...] atores-chave nos esforços da região para melhorar a qualidade e os resultados educativos" (BRUNS; LUQUE, 2014 , p. 11. Ademais, e consonante com a lógica economicista inerente ao organismo patrocinador do estudo, os autores ressaltam o fato de que "[...] embora a importância de um bom ensino possa parecer evidente, nas pesquisas educacionais, nos últimos 10 anos, se começou a quantificar o grande 
impacto econômico da qualidade dos professores" (BRUNS; LUQUE, 2014, p. 1).

documento ora referenciado, seguindo roteiro comum às produções do Banco, após as constatações introdutórias, apresenta um panorama do que denomina como qualidade dos professores da educação básica, construído a partir de estudos que compuseram "[...] a maior base de dados comparados da história, no nível mundial, sobre prática docente em sala de aula, com observações de mais de 15.000 professores de sete países da América Latina e do Caribe" (FAMILIAR; TULUY; DE LA TORRE; COSTIN, 2014, p. XII).

Com respaldo nesses dados, os dois primeiros capítulos da publicação - ¿ Quiénes son los profesores de América Latina y el Caribe? e Dentro de las aulas de América Latina y el Caribe - traçam o perfil dos professores no universo pesquisado, que, na ótica do Banco, são, predominantemente, mulheres, de posição socioeconômica relativamente baixa", com "[...] elevados níveis de educação, mas escassas capacidades cognitivas [...]", academicamente menos sólidos que o conjunto geral da educação superior [...], portanto, com [...] aspirações acadêmicas mais limitadas" (BRUNS; LUQUE, 2014, p. 7).

Quanto à formação docente, as propostas apresentadas no docu124 mento - e sintetizadas em Rodrigues (2015) - consideram, como mais eficazes, programas centrados no trabalho a ser desenvolvido, pelos professores, em sala de aula. Tais propostas convergem, ainda, para minimizar a formação inicial e valorizar o que os autores denominam de "certificação alternativa" (BRUNS; LUQUE, 2014, p. 31 ), ou seja, a certificação, conferida a profissionais formados em outras disciplinas ou áreas, por programas como o Teach for America (Ensina para a América).

Na apreciação dos autores, constitui um avanço o fato de vários países do subcontinente haverem implementado, desde o ano de 2007, seções da rede Teach for All (Ensina para Todos), o que permitiu a países como "Chile, Peru, México, Colômbia, Argentina e Brasil recrutaram profissionais de primeiro nível, de outras disciplinas, [...] dispostos a dedicarem dois anos ao ensino em escolas de zonas sumamente desfavorecidas" (BRUNS; LUQUE, 2014, p. 31).

Para Ball, Bailey, Mena, Del Monte, Santori, Tseng, Young e Olmedo (2013), esses cursos de capacitação, "menos acadêmicos e mais flexíveis", constituem exemplo do reducionismo e da racionalização da formação de professores, característicos da desprofissionalização e da desqualificação 
docente, observadas em âmbito mundial. Para os autores, as iniciativas do Teach for All, desenvolvidas no Brasil, Chile, Argentina, Israel, Líbano, China, Alemanha, Estônia, Letônia, Lituânia, Bulgária e Austrália,

[...] removem muito do conteúdo teórico e crítico da formação docente e visam colocar estudantes recém-graduados, os mais bem qualificados, em salas de aula de escolas "desafiadoras" após poucas semanas de treinamento para um compromisso de dois anos. São iniciativas basicamente financiadas por corporações filantrópicas, embora possam ser também subsidiadas com verba pública, e são o exemplo do aumento da presença do setor privado como peça chave, globalmente falando, para as políticas educacionais e para a prestação de serviços; a Fundação Bill e Melinda Gates é uma dentre inúmeras organizações filantrópicas que, por exemplo, financiam Teach For America, e na Inglaterra vários bancos comerciais e de investimentos, tais como HSBC e Goldman Sachs, também estão muito envolvidos (BALL; BAlLEY; MENA; DEL MONTE; SANTORI; TSENG; YOUNG; OLMEDO, 2013 , p. 17).

Retomando as formulações do documento do BM, a capacitação do futuro professor seria aferida por meio de "[...] exame de certificação ou prova de capacidade para selecionar os candidatos a ocupar postos docentes" (BRUNS; LUQUE, 2014, p. 29). Esses "exames de egresso", além de "melhorar a contratação dos professores", contribuiriam para "verificar o nível dos graduados ao longo do tempo e manifestar as diferenças de qualidade entre os institutos de formação", do que constituem exemplos, segundo o documento, a "Prova Inicia do Chile, estabelecida em 2008, e o exame nacional de professores que se está elaborando no Brasil (Prova Nacional de Concurso para o Ingresso na Carreira Docente)" (BRUNS; LUQUE, 2014, p. 30-31).

Ademais, alegando respaldo "na bibliografia acadêmica" referente "aos sistemas educativos 'que estão melhorando'", o documento aponta "[...] quatro estratégias amplas mais pertinentes [que uma ineficiente formação inicial prévia ao exercício profissional]" para a formação docente na América Latina e no Caribe (BRUNS; LUQUE, 2014, p. 37). De cunho simplesmente instrumental, essa capacitação, precipuamente:

- visaria "[... suprir as lacunas ou aprofundar os conhecimentos dos professores sobre as matérias que ministram e sobre como ensiná-los eficazmente [...]", mediante guias ou roteiros para o emprego, pelo professor, de [...] estratégias 
pedagógicas específicas e materiais complementares no ensino de um plano de estudos diário bem definido" (BRUNS; LUQUE, 2014, p. 37);

- teria como foco a gestão de aula, compreendendo o planejamento das aulas, o "[...] uso eficaz do tempo, das estratégias para manter a atenção dos estudantes e das técnicas de ensino mais eficazes" (BRUNS; LUQUE, 2014, p. 37).

Ratificando a articulação de conhecimentos específicos e ensino eficaz, o documento apresenta, ainda, experiências de capacitação em serviço, desenvolvidas por "[...] um número crescente de ministérios" na Região e "secretarias no Brasil" [...] mediante a criação de [...] institutos que promovem formação pedagógica em serviço, com o fim de tomar o controle direto dos conteúdos e da implementação do desenvolvimento profissional docente" (BRUNS; LUQUE, 2014, p. 38).

Em acréscimo, consideramos pertinente concluir este item ratificando orientações do Banco Mundial para a formação do professor da educação básica, mediante uma ligeira referência a um outro documento, elaborado pelos mesmos autores do anteriormente referido e dirigido especificamente ao Brasil, Atingindo uma educação de nível mundial no Brasil: próximos passos 126 (BRUNS; EVANS; LUQUE, 20111 .

Alegando respaldo na avaliação comparativa do Brasil com os países integrantes da $\mathrm{OCDE}$, o estudo destaca os quatro desafios principais para a educação brasileira de 2010-2020, o primeiro dos quais concerne à melhoria da qualidade dos professores ${ }^{4}$. Mantendo nosso entendimento de os documentos explicitarem, nitidamente, as concepções dos organismos, apresentaremos um excerto do sumário executivo do estudo ora referido, por considerar que, embora longa, se trata de uma citação imprescindível, por sua clareza e contundência.

No Brasil, a carreira docente se tornou uma profissão de baixa categoria que não consegue atrair os candidatos de alto rendimento acadêmico. Os dados indicam que os professores são recrutados do terço inferior dos estudantes do ensino médio - contrastando com a Singapura, Coréia e Finlândia, onde os professores vêm do terço superior. A melhoria da qualidade dos professores no Brasil exigirá o recrutamento de indivíduos de mais alta capacidade, o apoio ao melhoramento contínuo da prática, e a recompensa pelo desempenho. Tanto o governo federal quanto alguns governos 
estaduais e locais já iniciaram reformas nessas áreas, com programas de bônus para professores nos estados de Minas Gerais, Pernambuco e São Paulo e no município do Rio de Janeiro. Com o apoio da equipe de educação do Banco Mundial, esses sistemas escolares também estão usando métodos padronizados de observação em sala de aula desenvolvidos nos países da OCDE para olhar dentro da "caixa-preta" da sala de aula e identificar quais são os exemplos de boas práticas de professores que podem ancorar os seus programas de desenvolvimento profissional.

[...] Em vez de cursos teóricos, os programas de formação profissional projetados a partir das evidências das observações em sala de aula usam vídeos e exercícios práticos para ensinar técnicas eficazes de uso do tempo na sala de aula, do uso de materiais de aprendizagem e para manter os estudantes ocupados na tarefa. Este treinamento voltado para a prática é a nova direção na qual os países da $\mathrm{OCDE}$ estão partindo, e os estados mencionados anteriormente (Pernambuco e Minas Gerais) e o município do Rio de Janeiro estão na vanguarda (BRUNS; EVANS; LUQUE, 2011 , p. 6).

Ressaltamos, preliminarmente, a sintonia dos documentos do BM e da $O C D E$, relativamente à difusão de uma imagem pejorativa do professor licenciado, conforme pode ser constatado nas citações aqui apresentadas. Tal sintonia também se evidencia nas propostas do BM para a formação docente, pautada, assim como as da OCDE, na lógica economicista, defendendo o aligeiramento da formação, quando priorizam a formação continuada, com um caráter nitidamente instrumental, em detrimento de uma sólida formação inicial.

Ademais, os documentos representam um risco iminente de a formação universitária ser substituída por "rotas alternativas", "[...] programas de formação profissional projetados a partir das evidências [...] ou "programas de imersão" como os que já se encontram em desenvolvimento nos Estados Unidos e em alguns outros países, formando [...] professores como meros executores de scripts de ensino elaborados por outros" (COMPTON; WEINER, 2008 apud ZEICHNER, 2013, p. 35).

No limite, essas propostas contêm o risco de que a formação seja substituída pela certificação, por meio de provas de ingresso no magistério, permitindo atrair profissionais de outras áreas para curtos períodos de exercício como professores "em escolas de zonas sumamente desfavorecidas", reforçando, perversamente, as desigualdades sociais. 
Trilhando o caminho traçado por esses organismos, do núcleo estratégico do governo federal brasileiro emana, no último ano do período considerado, um documento que, colocando "[...] em questão [...] se as rotas institucionais para o exercício das carreiras de magistério da educação básica no país são eficazes - e se poderiam ser melhoradas" (SQUEFF, 2014, p. 5), apresenta propostas similares às indicadas nos documentos até aqui focalizados.

\section{(Re)Formulação nacional da agenda dos organismos internacionais?}

Publicado em abril/2014, integrando um número especial do boletim Radar - dedicado à temática Formação profissional e mercado de trabalho-e tendo, por autores, funcionários do Instituto de Pesquisa Econômica Aplicada (IPEA), o artigo Subsídios e proposições preliminares para um debate sobre o magistério da educação básica no Brasil, constitui, a nosso ver, uma objetivação emblemática do consentimento ativo do governo federal brasileiro e dos seus intelectuais orgânicos ${ }^{5}$ às concepções e orientações expressas, nos documentos dos organismos internacionais aqui considerados, acerca da formação inicial de professores da educação básica, embora a eles não seja feita qualquer referência explícita no artigo em foco ${ }^{6}$.

Os autores iniciam seu texto contrapondo duas afirmativas: a primeira, de o Brasil ser um país com reduzido percentual da população formado no nível superior; a segunda, de ser "[...] um dos países que mais formam profissionais da educação no mundo, ao menos em termos da participação de diplomados nos cursos de educação no total de graduados no ensino superior" (NASCIMENTO; SILVA; SILVA, 2014, p. 37). A esta última, acrescentam que os cursos de Pedagogia concentram metade dos formados na grande área de educação.

Na sequência, explicitam qual o debate com que o artigo pretende contribuir, mesclando, em um mesmo parágrafo, formulações e terminologias do Banco Mundial, da OCDE e da retórica gerencial dos recursos humanos, como destacado na transcrição apresentada a seguir. 
Considerando que ainda se dispõe de pouca gente com educação terciária em sua força de trabalho em geral, torna-se menos relevante investigar se, no Brasil, os fluxos e os estoques desse ou daquele tipo de profissional da educação são baixos ou elevados. que importa discutir é se as rotas institucionais para o exercício das carreiras de magistério da educação básica são eficazes no país - e o que poderia ser feito para incrementá-las neste sentido (NASCIMENTO; SILVA; SILVA, 2014, p. 37).

Além da Introdução ora referida, o artigo compreende três seções, abordando: o magistério na estrutura da educação nacional (seção 2); três questões centrais no debate sobre a docência na educação básica - titulação adequada, precarização dos vínculos de trabalho e baixa atratividade financeira da carreira (seção 3), e, na seção 4, as conclusões e encaminhamentos gerais de política para a construção de um modelo nacional de certificação e recrutamento para o magistério da educação básica.

Na seção 2, os autores, contrapõem a habilitação para a docência na educação básica no Brasil à da maioria dos países, nos quais são adotados "mecanismos diversos de titulação, que não necessariamente passam por uma formação pedagógica em nível de graduação". Seguem, criticando a ausência de "[...] um sistema brasileiro de certificação de professores [...] de modo que a certificação [...] se confunde com a própria conclusão de uma das alternativas de cursos de formação inicial de professores, alternativas estas centradas nas licenciaturas de pedagogia e de disciplinas específicas" (NASCIMENTO; SILVA; SILVA, 2014, p. 39).

Enfeixando as constatações da seção destacada, os autores destacam a singularidade do Brasil,

[...] como exemplo de país que adota como majoritário o padrão de formação inicial e de certificação para a docência na educação básica centrado na titulação em nível de graduação, em grau de licenciatura e sem garantias de inserção na carreira aos que concluem os três a cinco anos desse percurso. Há países em que a formação pedagógica só é provida em formatos de cursos sequenciais pós-médios. Há países em que tanto cursos de graduação quanto outros formatos de formação pós-média ou até mesmo pós-graduação convivem como alternativas possíveis de formação docente. Além disso, há países em que a certificação é dissociada 
da formação inicial do professor (NASCIMENTO; SILVA; SILVA, 2014, p. 40).

Na terceira seção do artigo, em que são abordadas as três questões, consideradas, pelos autores, como centrais no debate sobre o magistério, o primeiro item ${ }^{7}$ - O problema da titulação adequada - volta a tratar, desta vez, com um tom mais abertamente questionador, do atrelamento (termo utilizado pelos autores), às licenciaturas plenas, da titulação exigida para credenciamento dos professores na educação básica. Para os articulistas, "a LDB parece tratar formação adequada como sinônimo de licenciatura na disciplina lecionada", induzindo, portanto, "[...] a redução do problema da formação adequada a uma questionável exigência de titulação específica, ou, mais concretamente, de grau de titulação acadêmica" (NASCIMENTO; SILVA; SILVA, 2014, p. 421.

Já construindo o argumento a ser apresentado ao final do item, os autores fazem referência à Resolução CNE n² 2/1997 (BRASIL. CNE, 1977), que instituiu, em caráter provisório, os programas especiais de formação pedagógica, destinado a graduados não-licenciados, visando suprir a carência de professores habilitados, em disciplinas e localidades determinadas. Após afirmarem que a citada Resolução adquiriu caráter perene, os autores questionam se a permanência desse dispositivo legal "[...] compromete a qualidade da educação básica brasileira [...]", opinando que, "provavelmente, não". Em sua opinião, [...] respostas tentativas a essa pergunta [...] serão obtidas por meio da associação de [...] dados sobre o desempenho estudantil em avaliações de larga escala com informações precisas sobre docentes e sobre estudantes [...] ou de [...] rigorosos controles estatísticos para minorar efeitos do fato de que a alocação de professores e de alunos a turmas não é aleatória" (NASCIMENTO; SILVA; SILVA, 2014, p. 43).

Criticando a suposição de que, aprioristicamente, os graduados em áreas aplicadas sejam considerados despreparados para a docência de disciplinas relacionadas a sua formação, os autores ponderam que, se "didática e domínio da disciplina, forem atributos realmente relevantes e desejáveis em um bom professor, em tese os licenciados teriam vantagens comparativas no primeiro quesito e os bacharéis e tecnólogos, no segundo". Assim entendendo, opinam que o mais lógico seria 
[...] institucionalizar de vez a possibilidade de todos os três graus (licenciatura, tecnologia e bacharelado) serem igualmente elegíveis à função docente, com a preocupação de intensificar nos licenciados o domínio do objeto de ensino e de submeter os tecnólogos e os bacharéis que almejem lecionar na educação básica a programas de desenvolvimento profissional focados em currículo, avaliação escolar, didática e em práticas e metodologias de ensino (NASCIMENTO; SILVA; SILVA, 2014, p. 43).

Conforme entendemos, os autores criticam a exigência da licenciatura plena, como requisito para o exercício do magistério na educação básica, por partilharem da concepção - presente nos documentos do BM e da OCDE - de que os licenciados são menos competentes que os bacharéis, não dominando os conteúdos específicos das disciplinas que irão lecionar, razão pela qual afirmam a provável vantagem comparativa dos licenciados no "quesito didática".

Fundamentadas nas constatações apresentadas, as Conclusões e possíveis encaminhamentos gerais de política constituem a última seção do artigo (Seção 4), em que os autores, embora reconheçam a competência legal dos sistemas estaduais e municipais, avocam o regime de colaboração e as funções cometidas à União, para afirmarem "[...] desejável um protagonismo do MEC nesta seara". Em consequência, propõem que as "[...] questões debatidas [no] artigo poderiam ser trabalhadas em uma política nacional de certificação e de recrutamento docente" (NASCIMENTO; SILVA; SILVA, 2014, p. 47).

A primeira das iniciativas propostas, diretamente vinculada à formação dos professores, seria a refomulação da Prova Nacional de Concurso para o Ingresso na Carreira Docente (Prova Docente), "[...] a fim de que esta assumisse concomitantemente o papel de instrumento de certificação e de recrutamento para o magistério" (NASCIMENTO; SILVA; SILVA, 2014, p. 47, grifos nossos).

Segundo os autores, adotada como instrumento de recrutamento, a Prova Docente "passaria a desempenhar um papel de referência para os cursos de licenciatura espalhados pelo Brasil". Embora considerando tal papel como relevante, os autores conferem centralidade à outra função prevista para a Prova, a certificação de professores, por compreenderem que "[...] uma atribuição adicional de certificação docente em âmbito nacional teria o potencial de engendrar uma revolução muito maior sobre o modelo de formação inicial de professores hoje vigente no país" (NASCIMENTO; SILVA; SILVA, 2014 , p. 47). 
A nosso ver, além da evidente sintonia com as proposições da OCDE e do BM, a proposta e sua justificativa guardam perfeita consonância com as orientações do governo federal, no campo das políticas educacionais, adotadas desde o Planejamento Político-Estratégico do primeiro mandato de Fernando Henrique Cardoso, replicadas em diversas ações, dos Parâmetros Curriculares Nacionais às avaliações em larga escala da educação básica: centralização das decisões no Ministério da Educação, como instância político-estratégica; uniformização e estreitamento curricular; controle sobre a formação e o trabalho docente.

Quanto à proposta da Prova Nacional, e mantendo a "[...] linha de argumentação [...] de que formação adequada não deva ser restringida à titulação em um ou em outro grau de educação acadêmica [...], os autores defendem que [...] deveriam ser elegíveis à Prova Docente como instrumento de certificação qualquer licenciado (a), bacharel(a) ou tecnólogo(a) disposto a ingressar no magistério da educação básica" (NASCIMENTO; SILVA; SILVA, 2014 , p. 47). Definem, ainda, dando contornos mais nítidos à proposta:

- Os conteúdos da prova - para professores na educação infantil ou nos anos iniciais do ensino fundamental, "[...] domínio de conhecimentos pedagógicos

132 e de outros necessários à atuação nessas etapas e em face às especificidades dessas fases da infância [...], para professores dos anos finais do ensino fundamental, [...] domínio de conhecimentos específicos da disciplina a que se deseja lecionar, aliado a noções de metodologias de ensino e de interdisciplinaridade" (p. 47);

- Os critérios adicionais de certificação para bacharéis e tecnólogos - além da aprovação na Prova Docente, conclusão com sucesso - anterior ou posterior à Prova - "[...] de um programa especial de formação pedagógica de 540 horas (nos moldes da Resolução no 2/1997)" (p. 47).

Acrescem, ainda, a recomendação de que "seria desejável", para a certificação, a "[...] definição de padrões mínimos de desempenho na Prova Docente [...], seja o avaliado licenciado, bacharel ou tecnólogo" (NASCIMENTO; SILVA; SILVA, 2014, p. 47).

Além da presumida melhoria do corpo docente, os formuladores da proposta consideram que sua implementação traria vantagens ao "profissional certificado" que contaria com um "banco nacional de vagas para ałuação no magistério" e às 
[...] redes de ensino (públicas ou privadas) [que] teriam então à disposição um banco de currículos de alcance nacional de docentes certificados e m cada um dos níveis, etapas e modalidades de ensino - o sistema de certificação poderia ser também estendido aos interessados em se especializar em públicos com necessidades educacionais especiais ou na educação de jovens e adultos (NASCIMENTO; SILVA; SILVA, 2014, p. 47).

Tais indicações fazem coro às proposições dos organismos internacionais aqui apresentadas, notadamente no que tange: ao deslocamento da formação para a certificação; à prevalência do domínio de conhecimentos pedagógicos em detrimento do conhecimento teórico, para os professores dos anos iniciais da educação formal; à desqualificação dos licenciados em prol de graduados com formação na disciplina específica a ser ensinada, implicando a flexibilização do exercício do magistério a pessoas com diferentes trajetos formativos; e, por fim, à reiterada ênfase produtivista em padrões mínimos de desempenho em uma prova estandardizada.

Por fim, os autores esclarecem que os "[...] chamados cursos normais de nível médio não seriam extintos em um sistema assim [...], ficando, a critério dos planos de carreira docente, elaborados no âmbito de cada unidade federativa, [...] precisar para quais planos de cargos e salários seriam elegíveis os que ingressassem na carreira com essa titulação - e como seria seu recrutamento, caso ficassem de fora do sistema de certificação" (NASCIMENTO; SILVA; SILVA, 2014, p. 48).

Assim, articuladamente às prescrições dos organismos multilaterais, a proposta dos citados técnicos do IPEA para a formação dos professores da educação básica delineia uma concepção de professor que corresponda - como trabalhador e como formador das novas gerações de trabalhadores - aos requisitos do atual estágio da acumulação capitalista e atue como intelectual orgânico da nova pedagogia da hegemonia.

\section{Considerações finais}

A primeira constatação que se impõe, à mais rápida leitura dos fragmentos destacados ao longo do presente texto, indica a confluência de concepções e proposições emanadas dos organismos aqui focalizados 
- OCDE, BM e IPEA - em direção ao amesquinhamento da formação inicial, ao qual se contrapõe o estímulo a meros processos de certificação.

Temos, aqui, um profundo desnaturamento da reivindicação que se constituiu em um consenso entre os educadores progressistas, ainda nos anos 1980, segundo a qual, uma sólida formação inicial no nível superior possibilitaria, aos professores, o domínio dos conhecimentos técnico-científicos necessários a sua atuação profissional, bem como a compreensão ético-política do objetivo maior do processo educativo, a formação humana dos alunos, como sujeitos históricos.

Conforme entendemos, a ofensiva contra os cursos de licenciatura objetiva cercear suas possibilidades contra-hegemônicas, uma vez que, nos cursos de formação de professores e na área da educação de modo mais amplo, o ideário hegemônico é ainda confrontado com a persistência do materialismo histórico como referencial teórico, de que a formulação e a disseminação da Pedagogia Histórico-Crítica constitui um exemplo.

Ainda como elemento dessa disputa pela hegemonia, no período aqui considerado, permaneceram em vigência iniciativas dirigidas ao controle e conformação - alinhamento, no léxico gerencial - dos currículos dos cursos de formação de professores, instauradas desde o final dos anos 1990, como sejam, as diretrizes nacionais curriculares e o processo de avaliação dos cursos e das instituições formadoras.

Tal conformação atingirá níveis mais elevados em caso de implementação da Prova Nacional de Concurso para o Ingresso na Carreira Docente, uma vez que, por se constituir um instrumento de certificação e recrutamento de professores, pautado em matrizes de referência bastante detalhadas, essa Prova teria a potência de moldar, efetivamente, o currículo dos cursos de licenciatura, homogeneizando nacionalmente e subsumindo, à ideologia dominante, a formação dos professores para a educação básica.

Como instrumento de certificação, essa Prova poderia chegar a substituir o curso específico de formação inicial, conforme constam dos documentos do Banco Mundial e do IPEA, abordados neste trabalho. Teríamos, então, uma esdrúxula situação em que um resultado em uma prova sobrepujaria todo um processo formativo, ou, por outro lado, um hipertrofiado Estado educador, por meio das matrizes de referência da Prova Nacional, imprimiria, na formação de professores, a "[...] estandardização do modo de pensar e de atuar 
em dimensões nacionais" (GRAMSCl, 2001, p. 260), ou seja, parafraseando Marx, o Estado - o governo federal, mais explicitamente - seria designado como o educador de todos os professores da educação básica.

Como indícios da atual política de formação de professores para a educação básica, entendemos que os destaques ora apresentados atestam a imperiosa necessidade da realização e disseminação de estudos acerca desse objeto, visando à construção, com as "armas da crítica", de argumentos para o enfrentamento das estratégias do Estado educador voltadas a tornar senso comum a concepção de professor "eficaz" e "excelente" para o capital, competentes para educar as novas gerações segundo os preceitos da sociabilidade requerida pelo atual momento da acumulação capitalista.

\section{Notas}

1 Intitulado $\bigcirc$ foco nos professores, compreende os itens: o foco cada vez mais forte sobre questões relativas ao professor; visão geral das diretrizes de políticas amplas; metodologia e participação dos países; organização do Relatório.

2 A saber: Cap. 2. Por que políticas para professores são importantes?; Cap. 3. Tornando a docência uma opção de carreira atraente; Cap. 4. Desenvolvendo conhecimentos e habilidades de professores; Cap. 5. Recrutando, selecionando e contratando professores; Cap. 6. Retendo nas escolas os professores eficazes: Cap. 7. Desenvolvendo e implementando políticas para professores.

$3 \bigcirc$ modelo simultâneo "é um programa em que disciplinas acadêmicas são estudadas paralelamente a estudos educacionais e profissionais, no decorrer de todo o curso" (OCDE, 2006, p. 108); modelo consecutivo "é um programa de capacitação profissional em pedagogia e docência, cursado após a conclusão de uma primeira graduação" (OCDE, 2006, p. 110).

4 Os outros três são: garantir o desenvolvimento infantil das crianças mais vulneráveis, construir um sistema de ensino médio de classe mundial, e maximizar o impacto das políticas federais de educação básica - e tirar proveito do "laboratório de ação educacional" brasileiro (BRUNS; EVANS; LUQUE, 20111 .

5 Consideramos o IPEA como um importante intelectual coletivo do bloco no poder, dada sua "missão" institucional de "produção e disseminação de conhecimentos e da assessoria ao Estado nas suas decisões estratégicas" (IPEA, sd).

6 Sem sequer citar - direta ou indiretamente - o Banco Mundial, o artigo apenas faz duas referências a produções técnico-estatísticas da OCDE: o relatório Education at a glance 2013, publicado pela Organização, e o manual Classificação Internacional Eurostat/Unesco/Ocde: áreas de formação e treinamento, publicação conjunta EUROSTAT, UNESCO e OCDE.

7 Os dois outros itens da seção - precarização dos vínculos de trabalho e baixa atratividade financeira da carreira - não serão abordados, por dizerem respeito ao trabalho docente, tema a que não nos voltamos, no momento. 


\section{Referências}

BALL, Stephen John.; BAILEY, Patrick; MENA, Paula; DEL MONTE, Pablo; SANTORI, Diego; TSENG, Chun-ying; YOUNG, Helen; OLMEDO, Antonio. A constituição da subjetividade docente no Brasil: um contexto global. Revista Educação em Questão, Natal, v. 46 n. 32, p. 9-36, maio/ago. 2013.

BRASIL. CONSELHO NACIONAL DE EDUCAÇÃO. Resolução CNE $\mathbf{n}^{\circ} \mathbf{2}$, de $\mathbf{2 6}$ de junho de 1977. Dispõe sobre os programas especiais de formação pedagógica de docentes para as disciplinas do currículo do ensino fundamental, do ensino médio e da educação profissional em nível médio. Disponível em: http://portal.mec.gov.br/cne/arquivos/pdf/ rcp002_97.pdf. Acesso em: 10 jun 2016.

BRASIL. Ministério das Relações Exteriores. Acordo Marco de Cooperação com a Organização para a Cooperação e Desenvolvimento Econômico (OCDE). Brasília, abr. 2015. Disponível em: http://www.itamaraty.gov.br/pt-BR/component/tags/tag/ 1 5-ocde-organizacao-para-a-cooperacao-e-o-desenvolvimento-economico. Acesso em: 14 out. 2015.

BRUNS, Barbara; LUQUE, Javier. Profesores excelentes: cómo mejorar el aprendizaje en América Latina y el Caribe. Grupo del Banco Mundial: Washington, DC, 2014. (Serie del Foro sobre Desarrollo de América Latina).

136 BRUNS, BÁRBARA. EVANS, David; LUQUE, Javier. Atingindo uma Educação de Nível Mundial no Brasil: próximos passos. Sumário Executivo. Publicações Banco Mundial. 2011. 8 p. Disponível em http://portal.mec.gov.br/ index.php?option=com_ docman\&view=download\&alias=7289-banco-mundi al-pdf\&category_slug =dezembro-2010-pdf\&ltemid=30192. Acesso em: 14 ago. 2013.

EVANGELISTA, Olinda; SHIROMA, Eneida Oto. Professor: protagonista e obstáculo da reforma. Educação e Pesquisa, São Paulo, v. 33, n. 3, p. 531-541, set./dez. 2007. Disponível em: <www.scielo.br/pdf/ep/v33n3/a10v33n3.pdf>. Acesso em: 15 set. 2014.

FAMILIAR, Jorge; TULUY, Hasan; DE LA TORRE, Augusto; COSTIN, Claudia. Prólogo. In: BRUNS, Barbara; LUQUE, Javier. Profesores excelentes: cómo mejorar el aprendizaje en América Latina y el Caribe Grupo del Banco Mundial. Washington, DC, 2014. p. 11-12. (Serie del Foro sobre Desarrollo de América Latina).

FRIGOTTO, Gaudêncio. Novos fetiches mercantis da pseudoteoria do capital humano no contexto do capitalismo tardio. In: ANDRADE, Juarez de; PAIVA, Lauriana Gonçalves de (Org.). As políticas públicas para a educação no Brasil contemporâneo. Juiz de Fora: EDUFJF, 2011. 
GRAMSCI, Antonio. Caderno do Cárcere 22: americanismo e fordismo. In: GRAMSCl, Antonio. Cadernos do Cárcere: temas de cultura. Ação católica. Americanismo e fordismo. Tradução Carlos Nelson Coutinho. Rio de Janeiro: Civilização Brasileira, 2001 . (v. 4).

KUENZER, Acacia Zeneida. As políticas de formação: a constituição da identidade do professor sobrante. Educação \& Sociedade, Campinas, v. 20, n. 68, p. 163-183, dez. 1999. INSTITUTO DE PESQUISA ECONÔMICA APLICADA (IPEA). O IPEA: Missão. Brasília, sd. Disponível em http://www.ipea.gov.br/portal/index.php?option= com content\&view=article\&id $=1227 \&$ ltemid=68. Acesso em 06 abr. 2017.

LEHER, Roberto. Um novo senhor da educação? A política do Banco Mundial para a periferia do capitalismo. Outubro, São Paulo, n. 3, p. 19-30, fev. 1999. Disponível em: outubrorevista.com. br/um-novo-senhor-da-educacao-a-politica-educacional-do-banco-mundial-para-a-periferia-do-capitalismo/. Acesso em: 20 jun. 2014.

MAUÉS, Olgaíses Cabral. A política da OCDE para a educação e a formação docente. A nova regulação? Educação, Porto Alegre, v. 34, n. 1, p. 75-85, jan./abr. 2011 . Disponível em: http://revistaseletronicas. pucrs.br/ojs/index.php/faced/article/viewFile/ 5033/ 6130. Acesso em: 26 set. 2013.

MELO, Adriana Almeida Sales de; SOUZA, Camila Azevedo; MELO, Marcelo Paula. Determinantes externos da formação para o trabalho simples. In: MARTINS, André Silva; NEVES, Lúcia Maria Wanderley (Org.). Educação básica: tragédia anunciada? São Paulo: Xamã, 2015.

NASCIMENTO, Paulo Meyer; SILVA, Carolina Andrade; SILVA, Paulo Henrique Dourado da. Subsídios e proposições preliminares para um debate sobre o magistério da educação básica no Brasil. Radar: tecnologia, produção e comércio exterior, Brasília, n. 32, p. 37-5 1, abr. 2014. (Edição Especial: Formação profissional e mercado de trabalho.

OCDE. Organização para Cooperação e Desenvolvimento Econômico. Professores são importantes: Atraindo, desenvolvendo e retendo professores eficazes. São Paulo: Coedição Moderna/ OCDE, 2006.

PIRES, Valdemir. Economia da educação: para além do capital humano. São Paulo: Cortez, 2005.

RODRIGUES, Melânia Mendonça. Neoprodutivismo e amesquinhamento da formação docente. Revista HISTEDBR, Campinas, n. 65, p.128-140, out. 2015. Disponível em: https://periodicos.sbu.unicamp.br/ojs/index.php/ histedbr/article/ view/8642701. Acesso em: 17 mar. 2017.

SAVIANI, Dermeval. História da ideias pedagógicas no Brasil. Campinas: Autores Associados, 2007. (Coleção memória da educação). 
SILVA, Maria Abadia de. Intervenção e consentimento: a política educacional do Banco Mundial. Campinas: Autores Associados/FAPESP, 2002.

SOUZA, Thaís Rabello de. (Con)formando professores eficazes: a relação política entre o Brasil e a Organização para a Cooperação e Desenvolvimento Econômico (OCDE). 2009. 300f. Dissertação (Mestrado em Educação) - Universidade Federal Fluminense, Niterói, 2009.

SQUEFF, Flávia de Holanda Schmidt. Apresentação. Radar: tecnologia, produção e comércio exterior, Brasília, n. 32, p. 5, abr. 2014. (Edição Especial Formação profissional e mercado de trabalho).

ZEICHNER, Kenneth. Políticas de formação de professores nos Estados Unidos: como e por que elas afetam vários países no mundo. Belo Horizonte: Autêntica, 2013.

\author{
Prof. a Dra. Melânia Mendonça Rodrigues \\ Universidade Federal de Campina Grande (Paraíba) \\ Unidade Acadêmica de Educação \\ Programa de Pós-Graduação em Educação \\ Grupo de Pesquisa em Política e Gestão Educacional \\ E-mail: melania.r@uol.com.br
}

Recebido 18 jun. 2018 Aceito 17 ago. 2018 